\title{
OPTIMUM PROBLEM OF PIEZOELECTRIC LAMINATED COMPOSITE PLATE USING GENETIC ALGORITHM
}

\author{
Le Kim Ngoc ${ }^{1}$, Tran Ich Thinh ${ }^{2}$ \\ ${ }^{1}$ Viet Nam Electricity, \\ ${ }^{2}$ Hanoi University of Technology
}

\begin{abstract}
The finite element model based on First Shear Displacement Theory to study the mechanical and electrical behaviors of cantilever laminated composite plate bonded piezoelectric patches on surface is presented. A nine-node isoparametric rectangular element with 5 degrees of freedom for the generalized displacements and 2 electrical degrees of freedom at each node is used. Optimization techniques based on genetic algorithm (GAs) are applied in order to maximize the piezoelectric actuator efficiency, improve the structural performance. The illustrative examples and results of the appropriate applied voltages, position of bonded piezoelectric actuator patches and fiber angle to achieve the desired displacement of the cantilever composite plate are presented.
\end{abstract}

\section{INTRODUCTION}

Base on the direct piezoelectric effect and converse piezoelectric effect, in the recent years, there has been an increase in the developments of the laminated composite plates integrated with piezoelectric materials. The composite constructures are bonded or embedded with piezoelectric layers or patches can greatly enhance the performance of existing structures such as sensory, adapting with static or dynamic responses as well as many application such as the shape control, nanopositioning, precision positioning...etc.

In order to search "best" results in static/dynamic control for structure with integrated piezoelectric actuators, many techniques are applied to solve this problem. The optimum problems are raised. Brij N. Agrawal et al. (1997) [1] used and improved available computer program to solve optimum problem on adaptive antenna shape control using piezoelectric actuators with the goal to find the optimum actuator voltage. Cristóvão M. Mota Soares et al. (1999) [2] used finite element models based on higher-order and firstorder displacement fields and the optimization procedure based on gradient method in order to find the optimum actuator voltage, the thicknesses of both substrate and piezoceramic layers, the fiber angles in each one of the Graphite/Epoxy layers. Sadri A. M. et al. (2002) [3] introduces a modelling approach based on the Rayleigh-Ritz assumed mode shape method to investigate the panel flutter suppression using a patch of piezoelectric materials bonded to the surface of the panel. They used genetic algorithm (GAs) as the search algorithm in order to find the best position to bond actuator. Xu B. et al. (2007) [4] used GAs for integrated optimization of structural topology and control for piezoelectric smart trusses. ... etc. 
In fact, the requirements on getting the desired displacement are becoming increasesingly important in the recent years, GAs has been extensively applied as a tool for optimization of engineering problems. In the present paper, we used nine-node isoparametric rectangular element with 5 DOF for the generalized displacements and 2 electrical DOF at each node based on FSDT and GAs are applied in order to find appropriate applied voltage, position of bonded piezoelectric actuator patches and fiber angle to achieve the desired displacement of the cantilever composite plate are presented.

\section{FINITE ELEMENT FORMULATION}

The displacement components $u, v$ and $w$ at any point in the laminate space in the $x, y$ and $z$ directions, respectively. The displacement field is expressed by:

$$
\begin{aligned}
& u(x, y, z)=u_{0}(x, y)+z \theta_{x}(x, y) \\
& v(x, y, z)=v_{0}(x, y)+z \theta_{y}(x, y) ; w(x, y, z)=w_{0}(x, y)
\end{aligned}
$$

where, $u_{0}, v_{0}$ and $w_{0}$ are the displacements of a point on the midplane in the $x, y$ and $z$ directions, and $\theta_{x}$ and $\theta_{y}$ are the rotations of normals to the midplane about the $y$ and $x$ axes, respectively.

For a piezoelectric material, the electrical and mechanical constitutive equations are coupled [5], [6] as follows:

$$
\begin{gathered}
\sigma=Q \varepsilon-e E, \\
D^{p}=e^{T} \varepsilon+p E
\end{gathered}
$$

here, $\sigma=\left\{\sigma_{x}, \sigma_{y}, \tau_{x y}, \tau_{y z}, \tau_{x z}\right\}^{T}$ is the elastic stress vector; $\varepsilon=\left\{\varepsilon_{x}, \varepsilon_{y}, \gamma_{x y}, \gamma_{y z}, \gamma_{x z}\right\}^{T}$ is the elastic strain vector; $Q$ is the stiffness matrix; $E$ is the electric field vector; $D^{p}$ is the electric displacements vector; $e$ is the piezoelectric stress coefficients matrix; $p$ is the permittivity coefficients matrix.

The FEM approximations are given by the following relations:

$$
\{u(\xi, \eta)\}=\sum_{i=1}^{n} N_{i}(\xi, \eta) \cdot\{u\}_{i}
$$

It is assumed that the piezoelectric layers are perfectly bonded. $\phi_{k}$ is vector of electric potential:

$$
\phi_{k}(\xi, \eta)=\sum_{i=1}^{n} N_{i}(\xi, \eta) \cdot \phi_{k}
$$

where, $N_{i}(\xi, \eta)$ are shape functions for mechanical and electrical fields, $u_{i}$ and $\phi_{k}$ are vectors of nodal displacement and electric potential.

Relating strain to displacement, and electric field to electric potential yields:

$$
\begin{aligned}
& \{\varepsilon\}=\left[\begin{array}{llllllll}
\varepsilon_{x}^{M} & \varepsilon_{y}^{M} & \varepsilon_{x y}^{M} & \varepsilon_{x}^{B} & \varepsilon_{y}^{B} & \varepsilon_{x y}^{B} & \gamma_{y z} & \gamma_{x z}
\end{array}\right]^{T}=[\partial]\left[\begin{array}{lllll}
u & v & w & \theta_{x} & \theta_{y}
\end{array}\right]^{T} \\
& =[\partial][N]\{u\}_{i}=\left[B_{u}\right]\{u\}_{i}
\end{aligned}
$$

A voltage $\phi$ applied across an actuator of layer thickness $t$ generates an electric field vector $\{E\}$, and electric field to electric potential yields:

$$
E_{k}=-\nabla \phi_{k}=\left\{\begin{array}{lll}
0 & 0 & E_{k}^{z}
\end{array}\right\} \quad \text { and } \quad E_{k}^{z}=-\phi_{k} / t_{k}=\left[B_{\phi}\right]\{\phi\},
$$


where, $t_{k}$ is the thickness of the $k^{t h}$ piezoelectric layer.

For static analysis, the finite element equations are written in condensation form as follows:

$$
\left[\begin{array}{ll}
K_{u u} & K_{u \phi} \\
K_{\phi u} & K_{\phi \phi}
\end{array}\right]\left\{\begin{array}{l}
u \\
\phi
\end{array}\right\}=\left\{\begin{array}{l}
F \\
Q_{c}
\end{array}\right\}
$$

here, $\boldsymbol{u}, \phi, F$ and $Q_{c}$ are the global vectors of displacement, electric potential, applied force and charge, respectively. In Eq. (9), the mechanical stiffness matrix, $K_{u u}$; mechanicalelectrical coupling stiffness matrix, $K_{u \phi}$; electrical-mechanical coupling stiffness matrix, $K_{\phi u}$; piezoelectric permittivity stiffness matrix, $K_{\phi \phi}$; applied force vector, $F$ and applied charge, $Q_{c}$ are defined in [7] [8] [9].

\section{STATEMENT OF OPTIMIZATION}

\subsection{Optimization problem}

The structural optimization problem can be stated as:

$\operatorname{Min}\{\Omega(\mathbf{b})\}$

Subject to: $b_{i}^{l} \leq b_{i} \leq b_{i}^{u}, i=1, \ldots, n \mathrm{~d} v$,

$$
\Psi_{j}(u, b) \leq 0, j=1, \ldots,
$$

where, $\Omega(\mathbf{b})$ is the objective function; $\Psi_{j}(u, b)$ are $m$ constraint inequalities, $\boldsymbol{u}$ is the displacement vector; $\mathbf{b}$ are design variables; $b_{i}^{l}$ and $b_{i}^{u}$ are the lower and upper limits of the design variables, respectively and $n d v$ is the total number of design variables.

The present approach is assumed that the shape of the plate is described by the transverse displacement $w$ in an arbitrary location in the $(x, y)$ plane. Let $\gamma_{i}$ and $w_{i}$ represent the desired transverse displacement and the actual transverse displacement corresponding to point $i$.

In order to control the displacement of the cantilever composite plate in static type situations, we use piezoelectric actuators with applied voltage. In the static shape control, all the piezoelectric patches are used as actuators to change deflection of the plate. The goal is to minimize the least error between the desired and the achieved displacement. Hence the following objective function can be written:

$$
\Omega_{p p}=\operatorname{abs}\left(\gamma_{i}-w_{i}\right)
$$

where, $p p$ sign is the "precision positioning"; abs represents absolute value.

We consider a cantilever composite plate, which is subjected to concentrate force at the middle point, $M$, of the free edge of the plate and we find the appropriate electrical voltages, position of bonded piezoelectric actuator patch pair and fiber angles of the laminated plate in order to transverse displacement of the point $M$ is minimum.

The problem statement:

In this example, the design variables are: the electrical voltage that should be applied to the piezoelectric actuators, $\phi_{i}$; the $(x, y)$ couple. Here, $x$ and $y$ are coordinates of point, $P$ and $P(x, y)$ is center of the piezoelectric patch pair. $P(x, y)$ position should be applied to bond actuator patch pair; the fiber angle, $\theta_{i}$ that should be used to the laminated composite plate. The present optimization problem can be written as:

$\operatorname{Min}\left\{\Omega_{p p}\right\}$ 


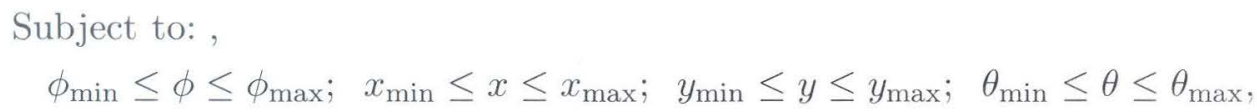

where, $\phi_{\min }$ and $\phi_{\max }$ represent the lower and upper voltage limits of the actuator; $x_{\min }$, $x_{\max }, y_{\min }$ and $y_{\max }$ represent limits of the dimensions of the plate; $\theta_{\min }$ and $\theta_{\max }$ represent the lower and upper fiber angle limits.

\subsection{Genetic algorithms (GAs)}

In this paper a GAs is used as the search algorithm and based on the code of Andrew Chipperfield, Carlos Fonseca and Hartmut Pohlheim (1994).

The GAs was first proposed by John Holland (1975) and developed by D.E Goldberg, L.David and Z. Michalevicz, the modeling of algorithms is illustrated in Fig. 1.

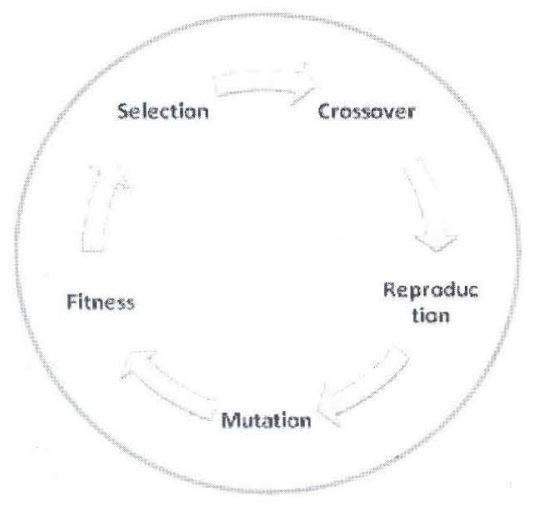

Fig. 1. The modeling of genetic algorithms

GAs are essentially random search techniques from the mechanics of natural genetics of population. In general, the fittest individuals of any population tend to reproduce and survive to the next generation, thus improving successive generations. Although randomized, GAs can efficiently explore the new generation with better fitness. GAs have been shown to solve linear and nonlinear problems through mutation, crossover and selection operations applied to individuals in the population. The use of a GA requires the determination of these fundamental issues: chromosome creation, fitness function, and the genetic operators making up the reproduction function, and termination criteria [10, 11]. The initial population of chromosomes is created randomly and the fitness function, which is defined by the user, is computed. The goal of the fitness function is to encode numerically, the performance of the chromosome. Then the chromosomes with the largest fitness scores are placed one or more times into amating subset and chromosomes with low fitness scores are removed from the population. In the next step genetic operators, crossover and mutation, are used. Two chromosomes from the mating subset are randomly selected. The probability that these chromosomes are crossed over is a user-controlled option. If the chromosomes are allowed to crossover, a recombination operator is employed to exchange genes to produce two new sets of chromosomes. If they are not allowed to mate, the chromosomes are placed into the next generation unchanged. The last operator, mutation, 
is applied to the individual genes in the chromosome based on probability of mutation. Amutation simply changes the value for a particular gene so that local maximum is not mistaken for a global maximum [10]. Thus, the population is full of newly created chromosomes and the process is repeated until the termination criteria, for instance the number of generations, is met.

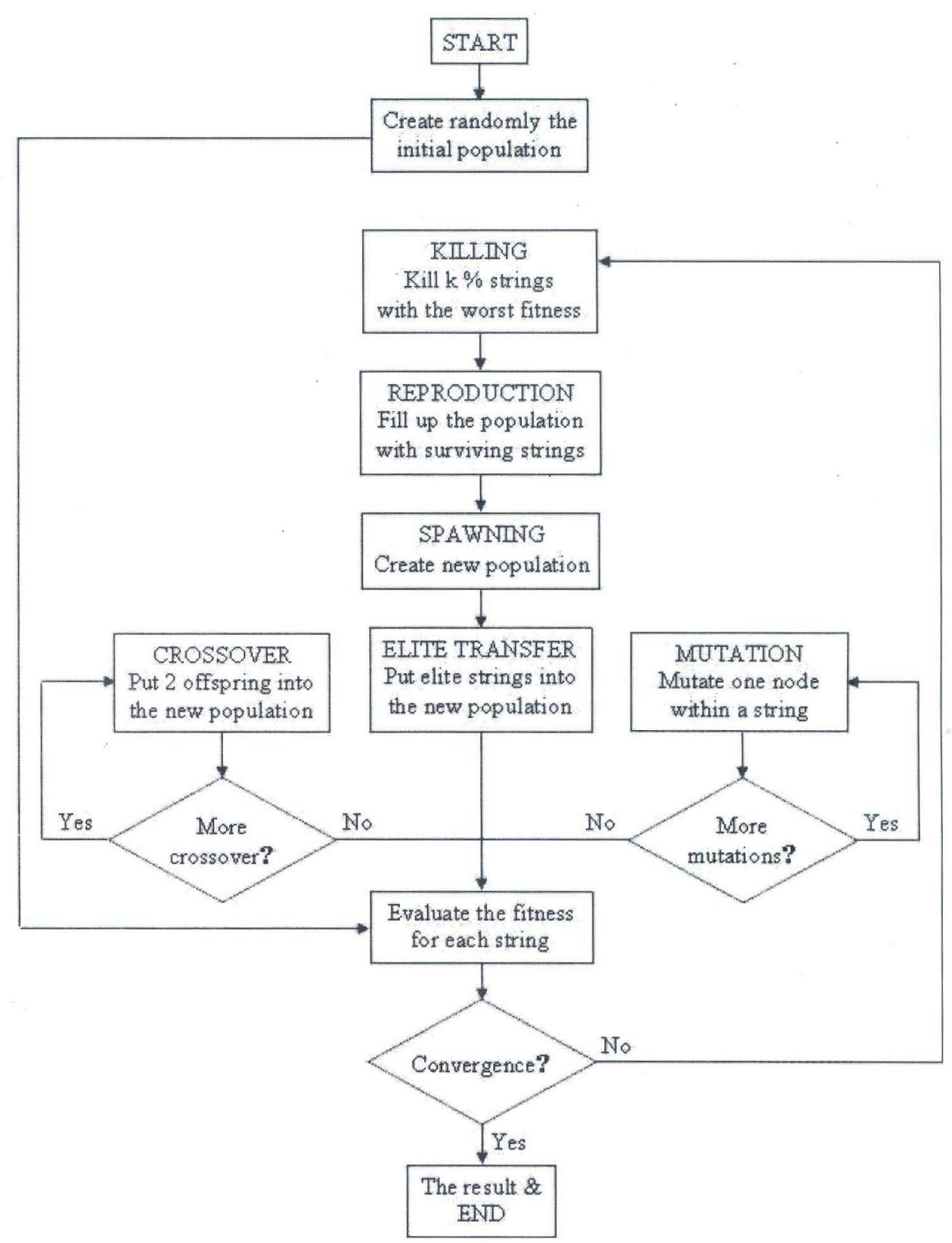

Fig. 2. Diagram of algorithm 
In this study, the application of GAs to determine the optimal electrical voltages, position of bonded piezoelectric actuator patch pair and fiber angles of the laminations for a cantilever plate is presented. To solve this problem, a simple GAs was used with the following configuration:

Population size $=10$

Crossover rate $=0.9$

Mutation rate $=0.001$

Number of generations $=250$.

The outline of the present optimization problem using the GAs is as follows [10]:

(1) The initial chromosomes of 10 are chosen randomly (population size). Each initial chromosome is a binary string which includes 10 bites and corresponds to the problem encoding. Four design variables (voltage, $\phi ; x, y$ coordinates and fiber angle, $\theta$ ) are chosen randomly and then encoded in each binary string. Solving (8) equation with four design variables gives an actual transverse displacement value, $w_{i}$ in (10). Each string is then evaluated and assigned a fitness value.

(2) The fitness value is calculated for each chromosome set (value of transverse displacement of the point, $\mathrm{M}$ corresponding to each chromosome set).

(3) Genetic operators are applied to produce a new set of chromosomes.

(4) Steps 1-3 are repeated (250 generations).

(5) The computation is terminated and the value set (include: voltage, $x, y$ coordinates, fiber angle) based on the best value (desired) of transverse displacement of the point, $\mathrm{M}$ from the current generation population is selected as the optimal result.

The flowchart of the algorithm is illustrated in Fig. 2.

\section{NUMERICAL EXAMPLE AND RESULTS}

Consider a cantilever plate: $L_{c} \times W_{c} \times t_{c}=160 \mathrm{~mm} \times 30 \mathrm{~mm} \times 1 \mathrm{~mm}$, which has four layers. The thickness of each layer is $t_{c} / 4$, made of graphite-epoxy (T300/976), and piezoelectric actuator patch pair (the symbols of the dimensions are shown in Fig. 3). The piezoelectric patch PZT G1195N: $\left.L_{p} \times W_{p} \times t_{p}=20 \mathrm{~mm} \times 10 \mathrm{~mm} \times 0.2 \mathrm{~mm}\right)$. The plate is subjected to a concentrate force at the point, $M$, of $0.1 \mathrm{~N}$. Material properties of PZT G1195N and T300/976 graphite-epoxy are shown in Table 1.

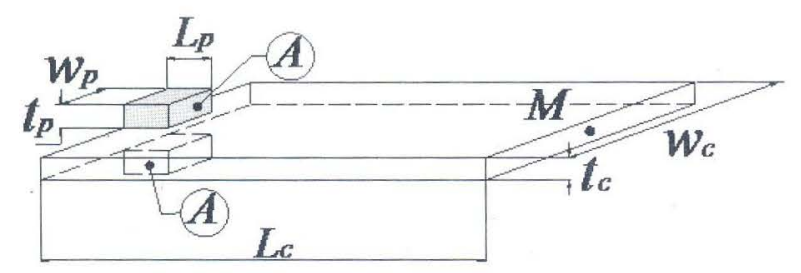

Fig. 3. The symbols of the dimensions of the cantilever plate and piezoelectric actuator patch pair

The goal is to minimize the least error between the desired and the achieved transverse displacement of the point $M$. 
Table 1. Material properties of PZT G1195N and T300/976 graphite-epoxy.

\begin{tabular}{|c|c|c|c|c|c|c|c|c|}
\hline Material & $\begin{array}{c}E_{11} \\
(\mathrm{GPa})\end{array}$ & $\begin{array}{c}E_{22}=E_{33} \\
(\mathrm{GPa})\end{array}$ & $\begin{array}{c}\nu_{12}=\nu_{13} \\
\nu_{13}=\nu_{23}\end{array}$ & $\begin{array}{c}G_{12}=G_{13} \\
(\mathrm{GPa})\end{array}$ & $\begin{array}{c}G_{23} \\
(\mathrm{GPa})\end{array}$ & $\begin{array}{c}d_{31}=d_{32} \\
(\mathrm{~m} / \mathrm{V})\end{array}$ & $\begin{array}{c}p_{11}=p_{22} \\
(\mathrm{~F} / \mathrm{m})\end{array}$ & $\begin{array}{c}p_{33} \\
(\mathrm{~F} / \mathrm{m})\end{array}$ \\
\hline PZT G1195N & 63.0 & 63.0 & 0.3 & 24.2 & 24.2 & $254 \times 10^{-12}$ & $15.3 \times 10^{-9}$ & $15 \times 10^{-9}$ \\
\hline T300/976 & 150.0 & 9.0 & 0.3 & 7.1 & 2.5 & - & - & - \\
\hline
\end{tabular}

First, we consider the single constraint (applied voltage) case, $x$ and $y$ are chosen equal to $10 \mathrm{~mm}$ and $15 \mathrm{~mm}$, respectively, and the composite plate with lamination sequence of $\left[0^{0} / 90^{\circ}\right]_{s}$ is chosen. We got the best result by using GAs is the same that by using classical way (shown in Table 2). Here, the classical way, it means we find the best result by calculating all possible cases.

Table 2. The results are achieved by using GAs, classical way in the single constraint case (applied voltage).

\begin{tabular}{|l|l|l|}
\hline & Using GAs & Using classical way \\
\hline $\operatorname{Min}\left\{a b s\left(\gamma_{M}-w_{M}\right)\right\}$ & $9.45 \times 10^{-9} \mathrm{~m}$ & $9.45 \times 10^{-9} \mathrm{~m}$ \\
\hline Appropriate applied voltages & 105.88 Volt & 105.88 Volt \\
\hline
\end{tabular}

Next, the multi-constrain optimization problem is considered.

We choose $\phi_{\min }$ and $\phi_{\max }$ equal to 0 and $200 \mathrm{~V}$, respectively; $x_{\min }, x_{\max }, y_{\min }$ and $y_{\max }$ are $10 \mathrm{~mm}, 150 \mathrm{~mm}, 5 \mathrm{~mm}$ and $25 \mathrm{~mm}$, respectively (depend on the dimensions of the cantilever plate and piezoelectric actuator patch pair); the chosen configuration of the plate is $\left[\theta /\left(90^{0}+\theta\right)\right]_{s}$ (type I) and $[\theta /-\theta / \theta /-\theta]$ (type II) with $\theta_{\min }$ and $\theta_{\max }$ equal to $0^{0}$ and $90^{\circ}$.

Corresponding with type I, the evolution of process in GAs with population size of 10 is shown in Fig. 4.

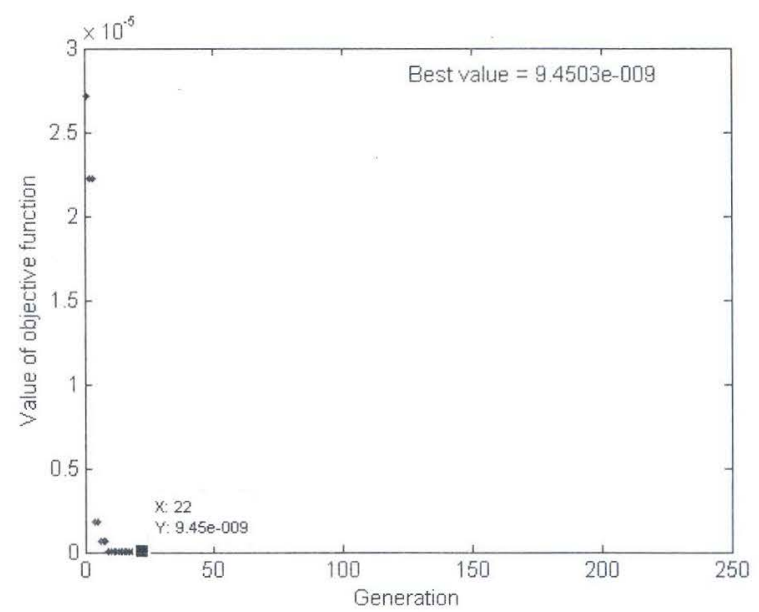

Fig. 4. (cor. with type I) Graph of evolutionary process in GA 
The achieved optimal result (cor. with type I) is $\phi=105.88$ Volt; $\quad x=10 \mathrm{~mm}$ $y=15 \mathrm{~mm} \quad \theta=0^{\circ}$.

These results together with the results shown in Table 2 gave us confidence on used algorithm, established program as well as achieved results.

The displacement of the cantilever plate with the achieved optimal result (cor. with type I) is shown in Fig. 5.

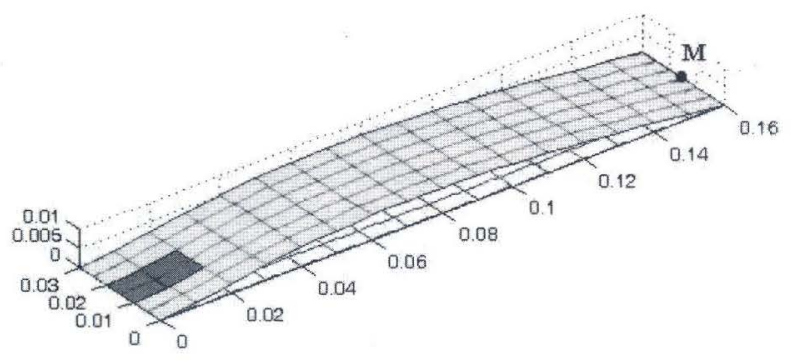

Fig. 5. (cor. with type I) The displacement of the cantilever plate

The transverse displacement of the center line and the point, $M$ with the achieved optimal result (cor. with type I) is shown in Fig. 6.

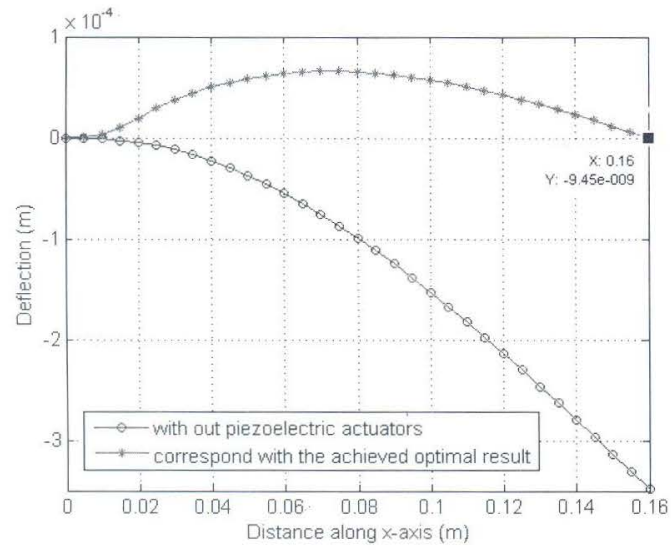

Fig. 6. (cor. with type I) The transverse displacement of the center line and the point, $M$

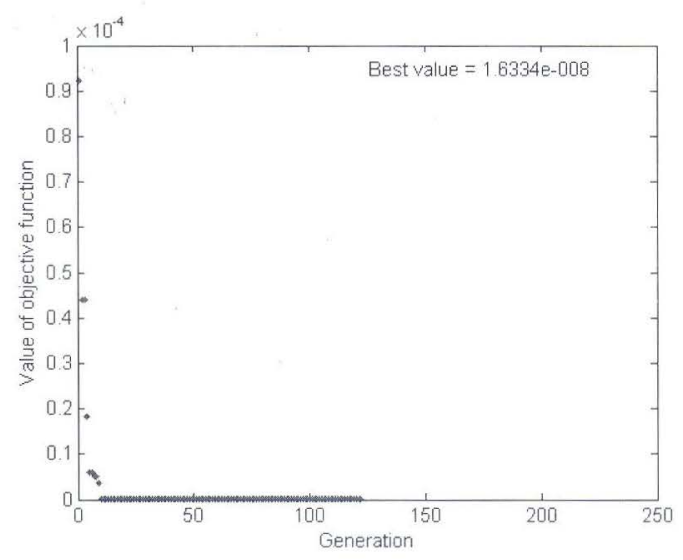

Fig. \%. (cor. with type II) Graph of evolutionary process in GA

Corresponding with type II, the evolution of process in GAs with population size of 10 is shown in Fig. 7.

The achieved optimal result (cor. with type II) is $\phi=121.31$ Volt $\quad x=10 \mathrm{~mm}$ $y=5 \mathrm{~mm} \quad \theta=15^{\circ}$.

These results together with the results shown in Table 2 gave us confidence on used algorithm, established program as well as achieved results.

The displacement of the cantilever plate with the achieved optimal result (cor. with type II) is shown in Fig. 8. 


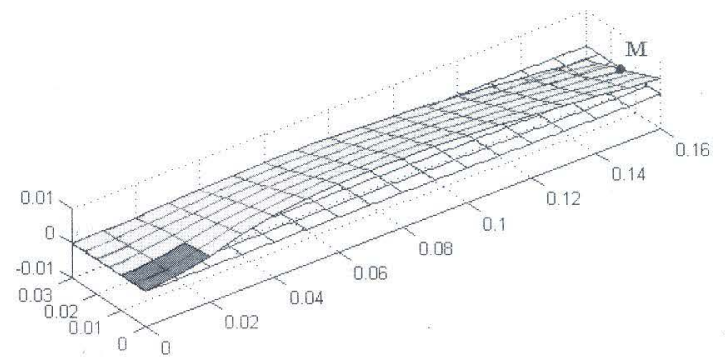

Fig. 8. (cor. with type II) The displacement of the cantilever plate

The transverse displacement of the center line and the point, $M$ with the achieved optimal result (cor. with type II) is shown in Fig. 9.

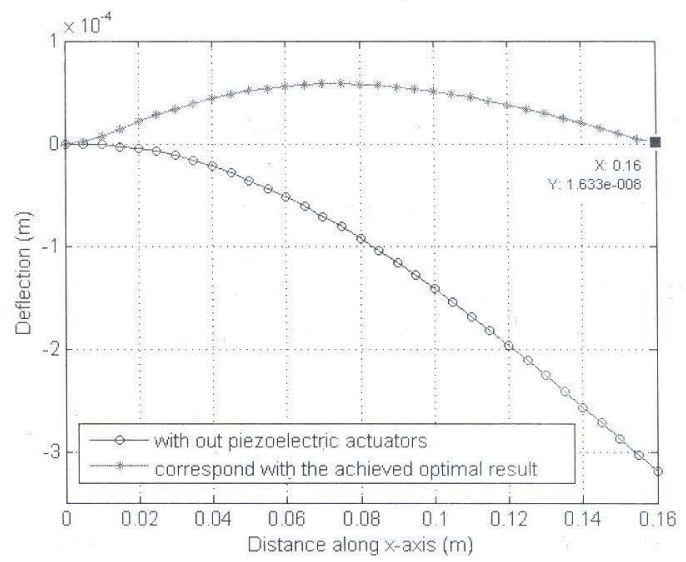

Fig. 9. (cor. with type I) The transverse displacement of the center line and the point, M.

\section{CONCLUSIONS}

Based on the FSDT, the present FEM algorithm, written program by Matlab and GAs is used as a search algorithm, the present optimization problem is solved. A cantilever composite plate is considered. The results of the appropriate applied voltages, position of bonded piezoelectric actuator patches and fiber angle of the laminations in order to get the desired displacement of the cantilever composite plate are achieved.

In the present optimization problem with four constrains (voltage, $\mathrm{x}, \mathrm{y}$ co-ordinate and fiber angle - design variables), we can see that the achieved optimal result depends on the chosen configuration of the plate, thus the configuration of the plate can be one of the design variables.

It can be seen that by calculating all possible cases for the present single constraint (applied voltage) problem gave us the desired results. However, in the multi-constraints (applied voltage, position to bond piezoelectric actuator patches and fiber angle of the laminated composite plate) problem, this classical way is not effective and therefore. it can't be used, the search algorithm, GAs is strong and confident. 


\section{ACKNOWLEDGEMENT}

This work is sponsored by the Ministry of Science and Technology.

\section{REFERENCES}

[1] Brij N. Agrawal, Adnan Elshafei M. and Gangbing Song (Spacecraft Research and Design Center (SRDC), Department of Aeronautics and Astronautics, U. S. Naval Postgraduate School, 1 University, Circle, Monterey, A 93940-5000, USA), Adaptive antenna shape control using piezoelectric actuators, Acta Astronautical 40 (1997) (11) 821-826.

[2] Cristóvão M. Mota Soares, Carlos A. Mota Soares and Victor M. Franco Correia, Optimal design of piezolaminated structures, Composite Structures 47 (1999) 625-634.

[3] Sadri A. M. ,Wright J. R. and Wynne R. J., LQG control design for panel flutter suppression using piezoelectric actuators, Smart Mater. Struct. 11 (2002) 834-839.

[4] Xu B. , Jiang J. S. and Ou J. P. , Integrated optimization of structural topology and control for piezoelectric smart trusses using genetic algorithm, Journal of Sound and Vibration 307 (2007) 393-427.

[5] José M. Simões Moita, Geometrically non-linear analysis of composite structutes with integrated piezoelectric sensor and actuator, Composite Structures 57 (2002) 253-261.

[6] Liu G. R., Dai K. Y. and Lim K. M., Static and vibration control of composite laminates integrated with piezoelectric sensors and actuators using the radial point interpolation method, Institute of Physics Publishing, Smart Mater. Struct. 13 (2004) 1438-1447.

[7] Tran Ich Thinh, Le Kim Ngoc, Mechanical analysis of the piezoelectric composite material, Proceedings of the eighth national conference on mechanics of solids, Thainguyen 8th (2006), pp. 814-822.

[8] Tran Ich Thinh, Le Kim Ngoc, Vibration of the piezoelectric composite plate, Proceedings of the eighth national conference on mechanic, Hanoi (2007), pp. 596-607.

[9] Tran Ich Thinh, Le Kim Ngoc, Shape and vibration control of composite plates with piezoelectric patches, The International Conference on Computational Solid Mechanics 11.2008.

[10] Goldberg D.E 1989 Genetic Algorithms in Search, Optimisation and Machine Learning (Reading, MA: Addison - Wesley)..

[11] Krishankumar K and Goldberg D.E 1992 Control system optimisation using genetic algorithms AIAAA J. Guidance, Control Dyn. May - June 735-9.

Received July 20, 2009

\section{BÀI TOÁN TỐI ƯU CHO TẤM COMPOSITE ÁP ĐIỆN SỬ DỤNG THUẬT TOÁN DI TRUYỀN}

Bài báo trình bày mô hình phần tử hữu hạn dựa trên lý thuyết biến dạng trượt bậc nhất để nghiên cứu ứng xử cơ điện của tấm chìa composite lớp có gắn những miếng kích thích áp điện trên bề mặt. Phần tử 9 nút đẳng tham số với 5 bậc tự do cơ và 2 bậc tự do điện thế tại mỗi nút được sử dụng. Thuật toán di truyền được dùng trong giải quyết bài toán tối ưu với mong muốn cực đại hiệu ứng kích thích áp điện, cải thiện khả năng làm việc của kết cấu. Bài báo đã đưa ra ví dụ số minh hoạ cùng kết quả về điện thế hợp lý áp đặt, vị trí hợp lý để dán những miếng kích thích áp điện và góc sợi hợp lý của composite lớp để đạt được chuyển vị mong muốn của tấm chìa composite. 